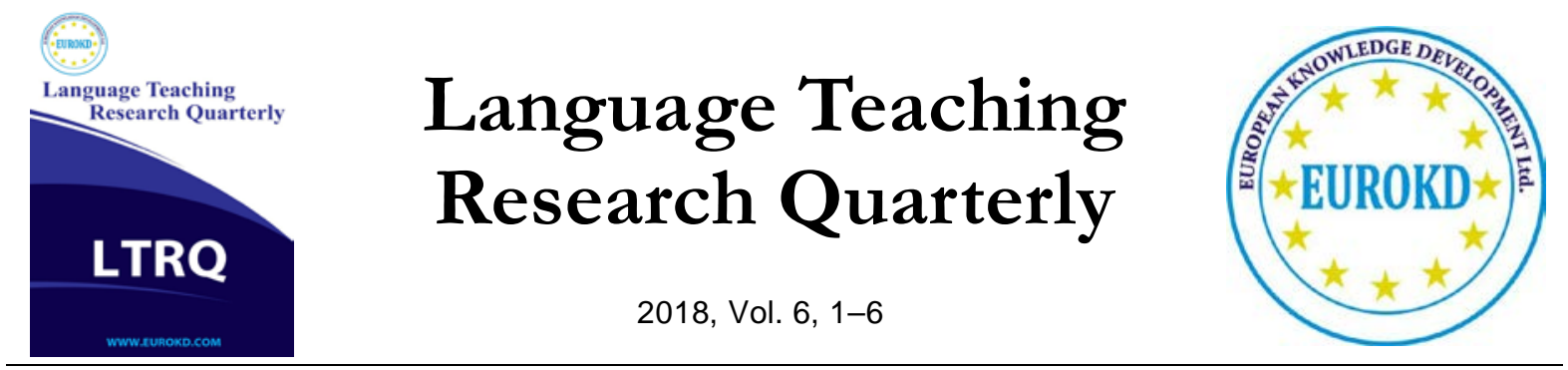

\title{
Written Corrective Feedback: The Road Ahead
}

\author{
Hayo Reinders ${ }^{1}$, Hassan Mohebbi ${ }^{2, *}$ \\ ${ }^{1}$ Unitec, New Zealand \\ ${ }^{2}$ University of Tehran, Iran
}

\begin{abstract}
Received 20 December 2017 Accepted 8 April 2018
Abstract

Over the past three decades, the role of written corrective feedback in improving L2 writing has been controversial. Although, a considerable amount of research has investigated WCF from a range of perspectives, limitations in the research design of many studies call into question the validity of their findings, thereby reducing their generalizability. This paper aims to further WCF research by investigating these limitations and offering suggestions for possible research designs, identifying key contextual variables and target structures, considering the roles of explicit and implicit knowledge, individual differences, and teachers' WCF proficiency levels and WCF beliefs.
\end{abstract}

Keywords: Writing; Written Corrective Feedback (WCF); Research Design Deficiencies; Explicit And Implicit Knowledge; Individual Differences

\section{Introduction}

Over the past three decades, the effect of written corrective feedback (WCF) on improving second language (L2) writing has been controversial (Ferris, 1999, 2004; Truscott, 1996, 1999). Some of the arguments against WCF (Truscott, 1996, 1999) are rooted in the fact that teachers' WCF practices are not in line with what some second language acquisition (SLA) theories assume. Krashen (1985), in line with Truscott, argues that WCF has no significant effect on learning a second language (for review, Bitchener, 2012).

Despite these concerns, WCF is an integral component of L2 writing instruction around the world. A number of theories and hypotheses in SLA, such as the Interaction Hypothesis, the Output Hypothesis, Sociocultural Theory, and Skill-Learning Theory, provide support for the role of 
corrective feedback in L2 learning and it has been demonstrated that employing WCF can result in greater grammatical accuracy in L2 writing (Ferris, 1997, 2015).

\section{WCF in English Language Teaching}

Ellis (2009) classifies WCF types firstly as either direct or indirect. In direct WCF, teachers give the correct form of an error in learners' writing. Direct WCF might involve crossing out a word or phrase which is redundant, adding a missing word or phrase, or giving the correct form or structure. As an explicit strategy, direct WCF may help reduce learners' confusion, especially those at the lower proficiency levels. It may even be proven to be more effective in resolving more complex errors in the learners' writing.

In indirect WCF, an L2 teacher indicates in some way that there are one or more errors in a learner's writing, but does not provide correction. Indirect WCF may involve underlining or circling the error, recording the number of errors in the margin of a given line, or using a code to show the place and the error type. L2 teachers are urged to give indirect WCF because it engages L2 learners in cognitive problem-solving (Ferris, 2004). Indirect WCF can provide an opportunity for L2 learners to reflect on their existing knowledge. Indirect WCF may result in more accurate writing because it is likely that L2 learners who receive indirect WCF invest a greater amount of time and processing effort, which may lead to deeper learning.

Next, WCF can be divided into focused and unfocused corrective feedback. In focused WCF, L2 teachers give feedback on pre-determined types of errors. In unfocused or comprehensive WCF, feedback is given to all or most of the errors learners make. Van Beuningen, De Jong, and Kuiken (2012) argued that unfocused WCF is more authentic than focused WCF. In contrast, Sheen, Wright, and Moldawa (2009) consider unfocused WCF to be an unsystematic strategy for correcting learners' written errors, which may overload L2 learners' attentional and working memory capacity.

It is reasonable to expect that L2 learners take advantage of focused WCF more than unfocused WCF because L2 teachers can consider learners' readiness and give selective feedback on one or two error types at a time. Consequently, learners may develop a deeper understanding of the nature of the error. Despite these arguments for and against focused and unfocused WCF, there is a gap in the literature preventing definitive statements at this point.

Next, WCF can be given by either a teacher or by peers. Both have advantages and drawbacks. Teacher WCF often leaves learners with little opportunity to choose which errors to correct. Peerfeedback may encourage more critical consideration on the part of the learner and provide more freedom. Drawbacks include the need for checking learners' L2 proficiency, model how to give WCF, and monitor peer WCF sessions. Also, there may be issues around varying social roles and cross-cultural dynamics within pairs or groups in peer WCF. Research findings on the influences of these variables are inconclusive and no clear advice can therefore be given for L2 writing instruction. 


\section{Future Directions: Expanding the Boundaries of WCF Research}

To-date, L2 researchers (Ferris, 1997, 1999, 2004; Sheen, Wright, \& Moldawa, 2009) have investigated the effect of WCF on improving writing accuracy of L2 learners from different perspectives. Despite this growing body of work, there remain a lot of unanswered questions.

Ferris (2010, for example) stresses the significant disagreements, conflicting theoretical and research approaches, and the wide range of practical applications In particular, three contextual variables in WCF research require further attention: (1) learner variables such as motivation, learning style, goals and L1; (2) situational variables like teacher, physical environment, and socioeconomic conditions; and (3) methodological variables including instructional design, what is taught and how it is taught (Evans, Hartshorn, McCollum, \& Wolfersberger, 2010).

The need for more targeted WCF research was also argued by Liu and Brown (2015). Specifically, the authors stressed that answers to key questions of whether and to what extent different types of WCF can promote L2 writing accuracy remain inconclusive at best. Their research indicated a number of methodological limitations and gaps, namely lack of comprehensive reporting of research context, methodology, and statistical analysis; low ecological validity of studies because of one-shot treatments and timed in-class writing tasks; mixed types of WCF as treatment for a single group of participants, resulting in mixed findings; and use of different accuracy measures, making comparison of studies difficult. Consequently, there is an urgent need to address these shortcomings in future studies if the issue of WCF effectiveness is to be addressed.

Ferris (2010) recommends the following:

- Contextualized and longitudinal designs: Studying whether the effect of WCF endures beyond revisions of the same text to subsequent, new pieces of writing.

- Revisions after WCF: Examining the potential role of including revisions in research designs.

- Types of WCF: The differential effect of direct and indirect WCF.

- Number and types of errors receiving WCF: The number and type of errors as target structure(s) and the nature of errors (i.e., treatable and untreatable).

- Individual and contextual differences: The role of individual differences such as motivation, learning style, and metalinguistic background knowledge in taking advantage of WCF.

Moreover, there is a need to clarify what kind of data a researcher should collect to support the claim that a learner's grammar has improved because of WCF. Polio (2012) provides four different options here:

- Revising a text using the WCF on a page

- Revising a text after having viewed WCF at some prior time

- Writing a completely new text soon after one treatment

- Writing a completely new text after several treatments over an extended period of time

Until now, the target structure in many studies has been the "definite" and "indefinite" article and the arguments for and/or against the efficacy of WCF are based on the findings of these studies. 
However, these results may not apply to other structures, such as tenses, modal auxiliary verbs, active and passive forms, connectives, and conditional sentences, to name a few.

Taking full advantage of the nature of the feedback offered in addressing a particular target structure is one of the many issues awaiting further empirical research. Both the problematicity and the learnability of the target structure, based on the participants' L2 proficiency, need to be taken into account when selecting target structures. Ferris (2002) distinguishes between treatable errors, related to rule-governed linguistic structures (i.e., a learner can self-correct it resorting to a grammar book or rules), and untreatable errors, such as word choice errors which are idiosyncratic, and which require learners to use previously acquired knowledge. Bitchener (2012) argues that rule-based errors may be more effectively corrected with WCF than complex errors. However, he warns that this is just a theoretical possibility, which needs to be tested systematically before firm claims may be made. The issue of whether different feedback strategies should be used for different grammatical structures is far from resolved and needs more in-depth investigation.

A key issue in WCF research and practice that has received surprisingly little attention is the role of explicit and implicit knowledge in L2 learning. Some authors such as Pawlak (2014; see Figure 1) have argued that corrective feedback can lead to the development of implicit knowledge (either directly, or by developing explicit knowledge which then can develop into implicit knowledge).

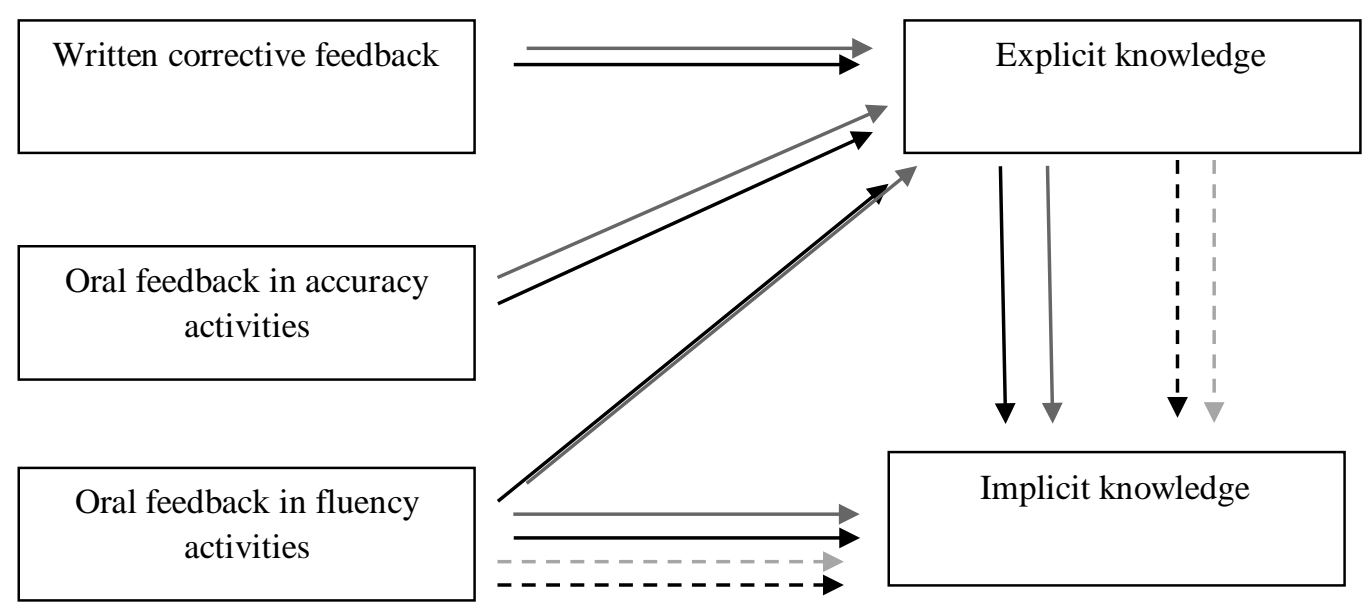

Figure 1.Potential contributions of oral and written corrective feedback to explicit and implicit knowledge

However, such a position is controversial and the relationship between corrective feedback and the development of implicit and explicit knowledge is not at all clear at this point.

Truscott (1996, 1999) has repeatedly argued that WCF can only help L2 learners develop explicit or declarative knowledge, not implicit knowledge, which is the ultimate goal of SLA (Bitchener \& Knoch, 2015. Bitchener (2012) has claimed that "we do know that written CF can play a role at least in terms of developing explicit knowledge and improved accuracy in the use of 
some L2 forms/structures” (p.361), but Bitchener and Knoch (2015) underscored that there is a gap in the research with regards the potential effect of WCF in converting explicit knowledge to implicit knowledge. Li (2014) found that the efficacy of oral corrective feedback was constrained by the explicitness of feedback provided, the proficiency level of learners, and the nature of the target linguistic structure.

To the best of our knowledge, Shintani and Ellis (2013) carried out the only study to date investigating the effect of direct WCF and metalinguistic explanation on learners' explicit and implicit knowledge. Surprisingly, the data analysis showed that direct WCF had no impact on explicit and implicit knowledge of the target structure (the English indefinite article). Although metalinguistic explanation helped the learners develop explicit knowledge of the target structure, but it had no significant effect on developing implicit knowledge.

Although individual differences have received a great deal of attention in SLA research in general, this is less so in the field of WCF. Examining the potential interactions between specific learner traits and specific educational conditions or treatments would be a valuable avenue for research.

In sum, in the L2 learning classroom context specifically, few empirical L2 research studies exist today that have closely examined L2 teachers' WCF practice and learners' preferences for WCF. Ferris (2014) goes so far as to claim that "the teachers' voices have been the missing link in the research base to date" (p. 6). In order to address this gap in the literature, there is a clear need to investigate L2 learners' perception about teachers' practices in writing instruction. The teachers' writing proficiency and their technical knowledge and WCF practices and ways of assessment are unfortunately underrepresented in research as well. Equally important, L2 learners' preferences about teachers' WCF strategies in L2 writing pedagogy require further attention. Moreover, teacher WCF and peer WCF need more empirical investigation in different classroom contexts.

Although teacher WCF is time-consuming, it is considered an effective and viable strategy and practice. Teachers' skill in teaching writing and WCF practice plays a vital role in their professional life. Therefore, we need to enhance the quality of WCF practice in language learning classrooms. More research is needed to improve the quality of writing instruction in L2 learning classrooms and to provide practical suggestions for teachers who give WCF. In addition, more and better preparation is required for teachers in this area and opportunities for ongoing professional development can play an important role here. In addition, through action research, teachers can help bridge the gap between theoretical and practical research in WCF.

\section{References}

Bitchener, J. (2012). A reflection on 'the language learning potential' of written CF. Journal of Second Language Writing, 21(4), 348-363.

Bitchener, J., \& Knoch, U. (2015). Written corrective feedback studies: Approximate replication of Bitchener \& Knoch (2010a) and Van Beuningen, De Jong \& Kuiken (2012).Language Teaching, 48(3), 405-414.

Ellis, R. (2009). A typology of written corrective feedback. ELT Journal, 63(2), 97-107. 
Ellis, R. (2005). Measuring implicit and explicit knowledge of a second language: A psychometric study. Studies in Second Language Acquisition, 27(2), 141-172.

Evans, N. W., Hartshorn, K. J., McCollum, R. M., \& Wolfersberger, M. (2010). Contextualizing corrective feedback in second language writing pedagogy. Language Teaching Research, 14(4), 445-463.

Ferris, D. R. (1997). The influence of teacher commentary on student revision. TESOL Quarterly, 31(2), 315-339.

Ferris, D. R. (1999). The case for grammar correction in L2 writing classes: A response to Truscott (1996). Journal of Second Language Writing, 8(1), 1-11.

Ferris, D. R. (2004). The "grammar correction" debate in L2 writing: Where are we, and where do we go from here? (and what do we do in the meantime...?). Journal of second language writing, 13(1), 49-62.

Ferris, D. R. (2002). Treatment of Error In Second Language Student Writing. Ann Arbor, MI: The University of Michigan Press.

Ferris, D. R. (2010). Second language writing research and written corrective feedback in SLA: Intersections and practical applications. Studies in Second Language Acquisition, 32(2), 181-201.

Ferris, D. (2011). Treatment of error in second language student writing. University of Michigan Press.

Ferris, D. R. (2014). Responding to student writing: Teachers' philosophies and practices. Assessing Writing, 19, 623.

Ferris, D. R. (2015). Written corrective feedback in L2 writing: Connors \& Lunsford (1988); Lunsford \& Lunsford (2008); Lalande (1982). Language Teaching, 48(4), 531-544.

Kang, E., \& Han, Z. (2015). The efficacy of written corrective feedback in improving L2 written accuracy: A metaanalysis. The Modern Language journal, 99(1), 1-18.

Krashen, S. D. (1985). The input hypothesis: Issues and implications. Addison-Wesley Longman Ltd.

$\mathrm{Li}, \mathrm{S}$. (2014). The interface between feedback type, L2 proficiency, and the nature of the linguistic target. Language Teaching Research, 18(3), 373-396.

Liu, Q., \& Brown, D. (2015). Methodological synthesis of research on the effectiveness of corrective feedback in L2 writing. Journal of Second Language Writing, 30, 66-81.

Pawlak, M. (2014). Error Correction in the Foreign Language Classroom: Reconsidering the Issues. New York: Springer.

Polio, C. (2012).The relevance of second language acquisition theory to the written error correction debate. Journal of Second Language Writing, 21(4), 375-389.

Sheen, Y., Wright, D., \& Moldawa, A. (2009). Differential effects of focused and unfocused written correction on the accurate use of grammatical forms by adult ESL learners. System, 37(4), 556-569.

Shintani, N., \& Ellis, R. (2013). The comparative effect of direct written corrective feedback and metalinguistic explanation on learners' explicit and implicit knowledge of the English indefinite article. Journal of Second Language Writing, 22(3), 286-306.

Truscott, J. (1996). The case against grammar correction in L2 writing classes. Language Learning, 46(2), 327-369.

Truscott, J. (1999). The case for "The case against grammar correction in L2 writing classes": A response to Ferris. Journal of Second Language Writing, 8(2), 111-122.

Van Beuningen, C., De Jong, N. H., \& Kuiken, F. (2012). Evidence on the effectiveness of comprehensive error correction in second language writing. Language Learning, 62(1), 1-41. 